\title{
New Log-Domain First-Order Multifunction Filter Using MOSFETs in Weak Inversion
}

\author{
Manoj Kumar Jain, Vinod Kumar Singh \\ Department of Electronics Engineering, Institute of Engineering and Technology, Lucknow, India \\ Email: mkjain71@gmail.com, vksingh@ietlucknow.edu
}

How to cite this paper: Jain, M.K. and Singh, V.K. (2016) New Log-Domain FirstOrder Multifunction Filter Using MOSFETs in Weak Inversion. Circuits and Systems, 7, 3522-3530.

http://dx.doi.org/10.4236/cs.2016.711299

Received: May 15, 2016

Accepted: May 28, 2016

Published: September 8, 2016

Copyright $\odot 2016$ by authors and Scientific Research Publishing Inc. This work is licensed under the Creative Commons Attribution International License (CC BY 4.0).

http://creativecommons.org/licenses/by/4.0/

\begin{abstract}
A new current-mode first-order log-domain multifunction filter is presented in this paper. This filter has single input and provides three outputs (low-pass, high-pass and all-pass) using a first-order low-pass filter and five of current mirrors as building blocks. The proposed filter employs only MOSFETs and a grounded capacitor. The first-order filters are used in audio and video applications extensively. The MOSFETs of the core section are operated in weak inversion thereby making the circuit suitable for low-voltage, low-power applications. The SPICE simulations have shown good performance of the proposed filter.
\end{abstract}

\section{Keywords}

Log-Domain Filters, Multifunction Filter, Translinear Circuits

\section{Introduction}

In 1979, Adams [1] proposed the concept of log-domain signal processing but this concept did not receive much attention of the researchers at that time. The power of log-domain technique came into popular focus only when Frey [2] [3] gave a generalized method to synthesize log-domain filters by using state-space technique. The principle of log-domain signal processing is to first compress (logarithmic) the input signal and then process it and finally expand (exponential) the signal at output stage. The working nature of log-domain filters is the same as that of companding circuits which were proposed by Tsividis, Gopinathan and Toth [4] independently in 1990. Thus, the log-domain circuits fall into the class of externally linear and internally nonlinear (ELIN) circuits. Adams circuit was the first ELIN circuit. The log-domain filters are also recognized as translinear (TL) filters (or dynamic translinear filters). The TL filter concept was reinvented by Seevinck [5] in 1990. 
Initially, log-domain filters were synthesized by using the exponential nature of bipolar transistor, but in 1994 Toumazou, Ngarmnil and Lande [6] proposed the first log-domain filter for implementation in MOS technology in which the MOS transistors were operated in subthreshold (or weak inversion) region. The literature survey up till 2014 shows that the log-domain filters have received more attention of the researchers during more than three decades [7].

The first-order filters have been extensively used in audio and video applications where circuit simplicity and power consumption are important parameters. Thus, during the last few decades, voltage-mode and current-mode first-order filter circuits have found significant place in literature. Among the voltage-mode and current-mode circuits, the latter fulfill the contemporary requirements such as low-power consumption, low-voltage operation, large dynamic range etc.; therefore, current-mode (CM) circuits have received much attention and from time to time, a number of current-mode firstorder multifunction (low-pass, high-pass and all-pass) filters [8]-[14] have been reported earlier in the literature by various researchers. Current-mode multifunction filters employing only bipolar junction transistors and a single grounded capacitor have been proposed by Kircay and Cam [8] [9] in 2006 and Arslanalp, Tola and Yuce [10] [11] in 2011. In 2014, Kircay [12] again proposed a multifunction ${ }^{1}$ filter using MOS transistors and single grounded capacitor. In this circuit [12], the MOS transistors have been operated in saturated region.

This paper proposes a MOS based multifunction first-order filter which is capable of realizing all possible first-order filters namely, low-pass, high-pas and all-pass from the same configuration. In the proposed circuit, the MOS transistors forming the core lowpass filter are operating in subthreshold region wherein MOS transistors have exponential characteristics. The validity of the proposed configuration has been confirmed through SPICE simulation results. The SPICE simulations show that the proposed circuit offers a performance which makes it suitable for low voltage, low power operation.

\section{Proposed Multifunction Filter Circuit}

The core block of the proposed circuit is a first-order low-pass filter which has been obtained by an appropriate modification of the four-MOSFETs translinear circuit used earlier as a normal product computation function [15]. The key concept to obtain multiple outputs from a single input signal is to subtract the low-pass signal from the input signal to get a high-pass response and then adding this high-pass output with the low-pass to get an all-pass output. In this sense, the methodology is similar to the one adopted in recent works [8] [9]. This is the first circuit of its kind in log-domain using CMOS technology.

The proposed circuit offers the advantage of the MOS transistors operating in subthreshold region [16]. This circuit includes a number of current steering circuits, at ap-

\footnotetext{
${ }^{1}$ Among other methods of creating first-order multifunction/ universal filters, which are based upon techniques other than log-domain/translinear/square-root domain approaches, one can count circuits of [13] [14]. But they have employed linear active building blocks named multiple output second generation current conveyor (MOCCII) and current differencing buffered amplifier (CDBA) respectively.
} 
propriate locations for minimizing $\mathrm{dc}$ offset and producing correct outputs.

In Figure 1 MOSFETs $M_{1}-M_{2}-M_{3}-M_{4}$ along with a capacitor $C$ constitute the basic first-order low-pass core. The transfer function of this circuit can be determined as follows. For the translinear loop comprised of $\mathrm{M}_{1}-\mathrm{M}_{2}-\mathrm{M}_{3}-\mathrm{M}_{4}$, we have the following equation for the close loop containing of $V_{G S}$ of the four-MOSFETs.

$$
V_{i}+V_{f}=V_{G S 3}+V_{1}
$$

If the MOS transistors are operated in weak inversion region they would have exponential relationship between drain current and gate source voltage [16] of the form

$$
I_{D}=I_{d 0} \mathrm{e}^{V_{G S} / n V_{T}}
$$

where $I_{d 0}$ is the zero bias current, $n=1.5$ is the subthreshold slope coefficient and $V_{T}$ $=k T / q=26 \mathrm{mV}$ at room temperature is known as thermal voltage.

Now Equation (2) can be rearranged as

$$
V_{G S}=n V_{T} \ln \left(\frac{I_{D}}{I_{d 0}}\right)
$$

Therefore Equation (1) can be written as

$$
n V_{T} \ln \left(\frac{I_{\text {in }}}{I_{d 0}}\right)+n V_{T} \ln \left(\frac{I_{f}}{I_{d 0}}\right)=n V_{T} \ln \left(\frac{s C V_{1}+I_{f}}{I_{d 0}}\right)+n V_{T} \ln \left(\frac{I_{\text {out }}}{I_{d 0}}\right)
$$

Equation (4) can be simplified as

$$
\ln \left(\frac{I_{\text {in }}}{I_{d 0}} * \frac{I_{f}}{I_{d 0}}\right)=\ln \left(\frac{s C V_{1}+I_{f}}{I_{d 0}} * \frac{I_{\text {out }}}{I_{d 0}}\right)
$$

From Equation (5), we finally obtain

$$
I_{\text {in }} * I_{f}=\left(C \dot{V}_{1}+I_{f}\right) * I_{\text {out }}
$$

The value of $\dot{V}$ can be obtained by differentiating Equation (2) and putting in Equation (6), thereby leading to

$$
I_{\text {in }} * I_{f}=\left(s C n V_{T}+I_{f}\right) * I_{\text {out }}
$$

Rearranging Equation (7), we get the transfer function of the circuit as

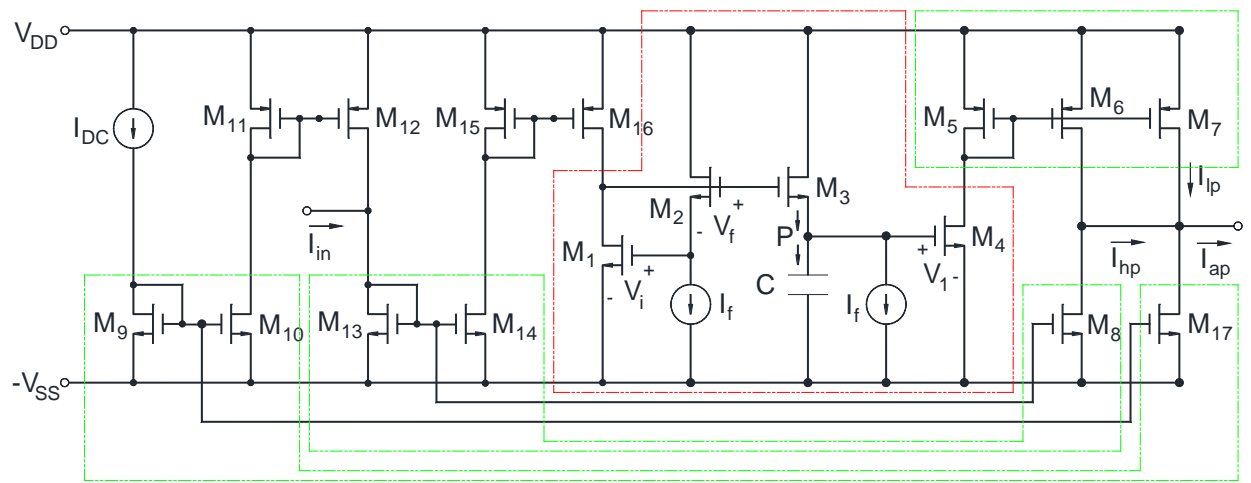

Figure 1. The proposed log-domain first-order multifunction filter. 


$$
\frac{I_{\text {out }}}{I_{\text {in }}}=\frac{I_{f} /\left(n C V_{T}\right)}{\left(s+I_{f} /\left(n C V_{T}\right)\right)}
$$

Equation (8) represents the transfer function of the first-order low-pass filter and can be expressed as:

$$
H(s)=\frac{I_{\text {out }}}{I_{\text {in }}}=\frac{\omega_{0}}{s+\omega_{0}}
$$

where $\omega_{0}=I_{f} /\left(n C V_{T}\right)$ is the cutoff frequency of the low-pass filter.

Now the low-pass output is given by

$$
I_{l p}=I_{\text {out }}
$$

whereas the other two current outputs namely, $I_{h p}$ and $I_{a p}$ are obtained by

$$
\begin{aligned}
& I_{\text {hp }}=I_{\text {out }}-I_{\text {in }} \\
& I_{\text {ap }}=2 I_{\text {out }}-I_{\text {in }}
\end{aligned}
$$

for which the required operations are carried out by the appropriate current mirrors and current repeaters as shown in Figure 1. The transistors $M_{9}-M_{10}-M_{17}, M_{13}-M_{14}-M_{8}$ and $M_{5}-M_{6}-M_{7}$ are current steering circuits and the MOSFET pairs $M_{11}-M_{12}$ and $\mathrm{M}_{15}-\mathrm{M}_{16}$ are simple current mirrors.

Thus, the transfer functions of the low-pass, high-pass and all-pass filters realized by the proposed circuit are given by

$$
\begin{aligned}
& H_{l p}=\frac{I_{l p}(s)}{I_{\text {in }}(s)}=\frac{\omega_{0}}{s+\omega_{0}} \\
& H_{h p}=\frac{I_{h p}(s)}{I_{\text {in }}(s)}=-\frac{s}{s+\omega_{0}} \\
& H_{a p}=\frac{I_{a p}(s)}{I_{\text {in }}(s)}=\frac{-s+\omega_{0}}{s+\omega_{0}}
\end{aligned}
$$

From Equations (13)-(15), it turns out that the cutoff frequency (in case of low-pass and high-pass) and phase (in case of all-pass) can be electronically tuned by changing the value of $I_{f}$ since $\omega_{0}=\frac{I_{f}}{n C V_{T}}$.

\section{SPICE Simulations}

The proposed circuit was simulated in SPICE employing TSMC $0.35 \mu \mathrm{m}$ Level 3 CMOS process parameters [17]. The selected parameters were $V_{D D}=-V_{S S}=0.5 \mathrm{~V}, C=3 \mathrm{pF}, I_{f}$ $=70 \mathrm{nA}, I_{o}=0.3 \mu \mathrm{A}$ and $I_{i n}=0.2 \mu \mathrm{A}$. The aspect ratios of the transistors were taken as shown in Table 2. From SPICE simulation, it has been verified that the condition required for weak inversion operation (of all the four MOSFETs $M_{1}-M_{2}-M_{3}-M_{4}$ of the basic low-pass core) i.e. $V_{G S}<V_{T}$ is satisfied.

The result of SPICE simulations of the circuit of Figure 1 using TSMC $0.35 \mu \mathrm{m}$ level 3 CMOS process parameters as given in Table 1 with aspect ratios of the MOSFETs as given in Table 2, are shown in Figures 2-5. Figure 2 shows the frequency response of 
Table 1. TSMC $0.35 \mu \mathrm{m}$ Level 3 CMOS process parameters.

\begin{tabular}{|c|c|c|}
\hline Parameters & NMOS & PMOS \\
\hline $\mathrm{L}$ & $1 \mathrm{U}$ & $1 \mathrm{U}$ \\
\hline $\mathrm{W}$ & $6 \mathrm{U}$ & $6 \mathrm{U}$ \\
\hline TOX & $7.9 \mathrm{E}-9$ & $7.9 \mathrm{E}-9$ \\
\hline NSUB & $1 \mathrm{E} 17$ & $1 \mathrm{E} 17$ \\
\hline GAMMA & 0.5827871 & 0.4083894 \\
\hline PHI & 0.7 & 0.7 \\
\hline VTO & 0.5445549 & -0.7140674 \\
\hline DELTA & 0 & 0 \\
\hline UO & 436.256147 & 212.2319801 \\
\hline ETA & 0 & $9.999762 \mathrm{E}-4$ \\
\hline THETA & 0.1749684 & 0.2020774 \\
\hline $\mathrm{KP}$ & $2.055786 \mathrm{E}-4$ & $6.733755 \mathrm{E}$ \\
\hline VMAX & $8.309444 \mathrm{E} 4$ & $1.181551 \mathrm{E} 5$ \\
\hline KAPPA & 0.2574081 & 1.5 \\
\hline $\mathrm{RSH}$ & 0.0559398 & 30.0712458 \\
\hline NFS & $1 \mathrm{E} 12$ & $1 \mathrm{E} 12$ \\
\hline TPG & 1 & -1 \\
\hline $\mathrm{XJ}$ & $3 \mathrm{E}-7$ & $2 \mathrm{E}-7$ \\
\hline $\mathrm{LD}$ & $3.162278 \mathrm{E}-11$ & $5.000001 \mathrm{E}-13$ \\
\hline WD & $7.04672 \mathrm{E}-8$ & $1.249872 \mathrm{E}-7$ \\
\hline CGDO & $2.82 \mathrm{E}-10$ & $3.09 \mathrm{E}-10$ \\
\hline CGSO & $2.82 \mathrm{E}-10$ & $3.09 \mathrm{E}-10$ \\
\hline CGBO & $1 \mathrm{E}-10$ & $1 \mathrm{E}-10$ \\
\hline CJ & $1 \mathrm{E}-3$ & $1.419508 \mathrm{E}-3$ \\
\hline $\mathrm{PB}$ & 0.9758533 & 0.8152753 \\
\hline MJ & 0.3448504 & 0.5 \\
\hline CJSW & $3.777852 \mathrm{E}-10$ & $4.813504 \mathrm{E}-10$ \\
\hline MJSW & 0.3508721 & 0.5 \\
\hline
\end{tabular}

Table 2. Aspect ratios.

\begin{tabular}{cc}
\hline MOS Transistors & W/L $(\mu \mathrm{m})$ \\
\hline $\mathrm{M}_{1}-\mathrm{M}_{7}, \mathrm{M}_{9}-\mathrm{M}_{17}$ & $6 / 1$ \\
$\mathrm{M}_{8}$ & $5.87 / 1$ \\
\hline
\end{tabular}




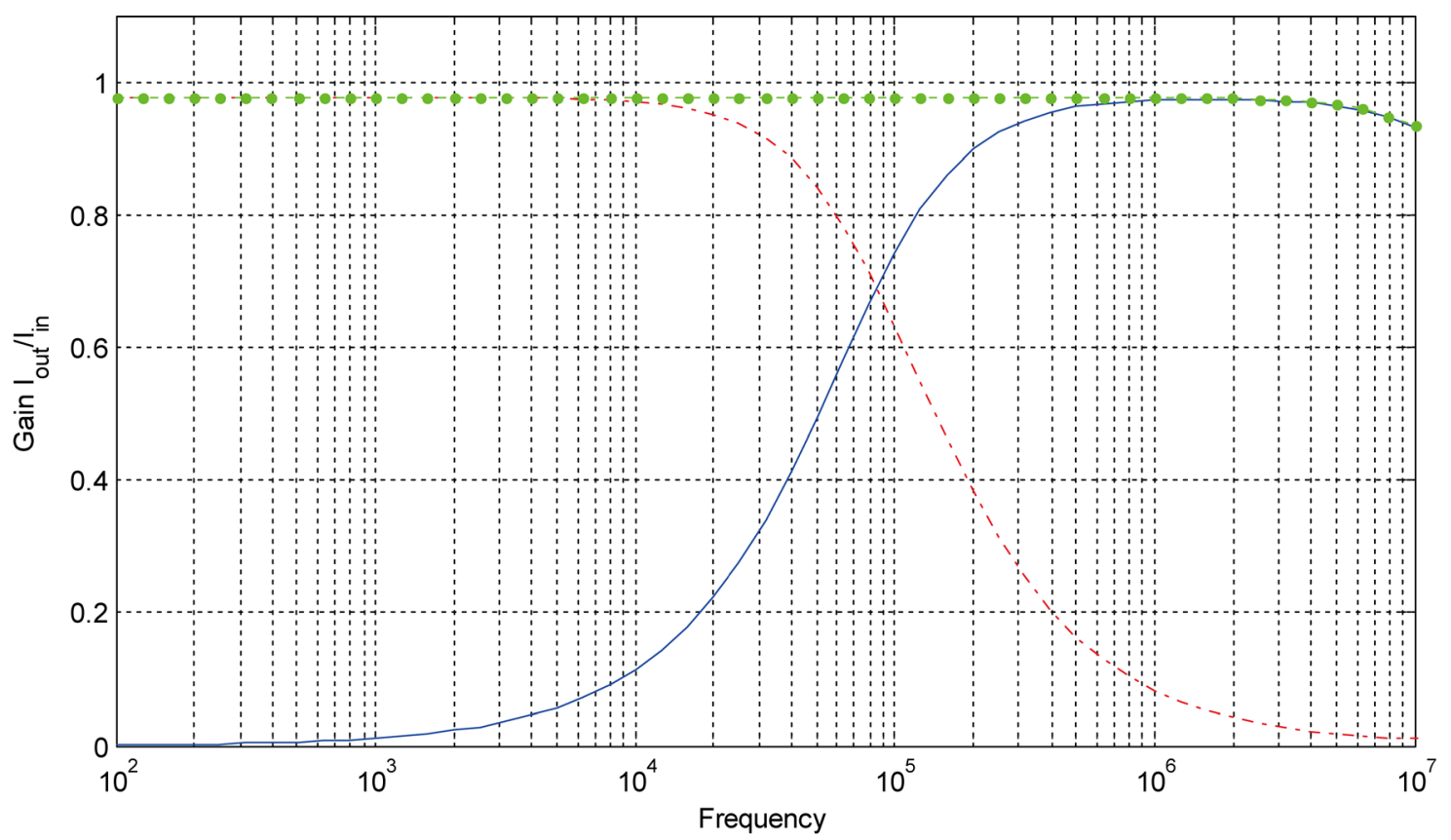

Figure 2. SPICE generated frequency response for the circuit of Figure 1 for $I_{f}=70 \mathrm{nA}$.

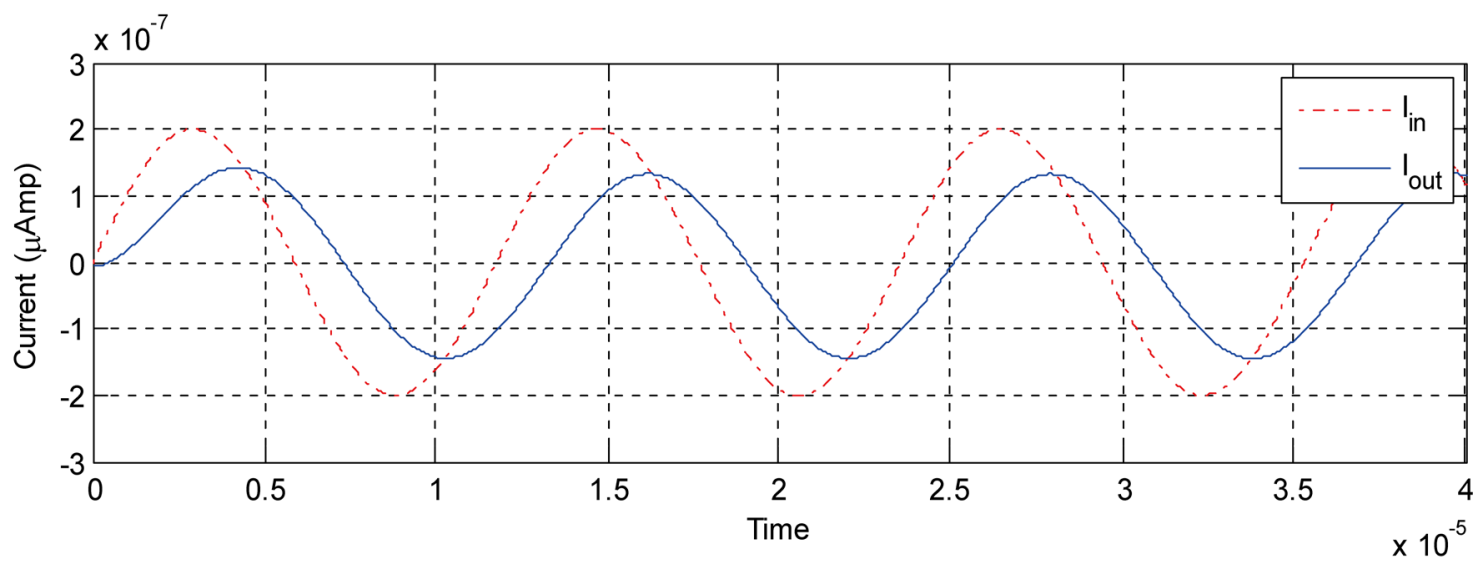

(a)

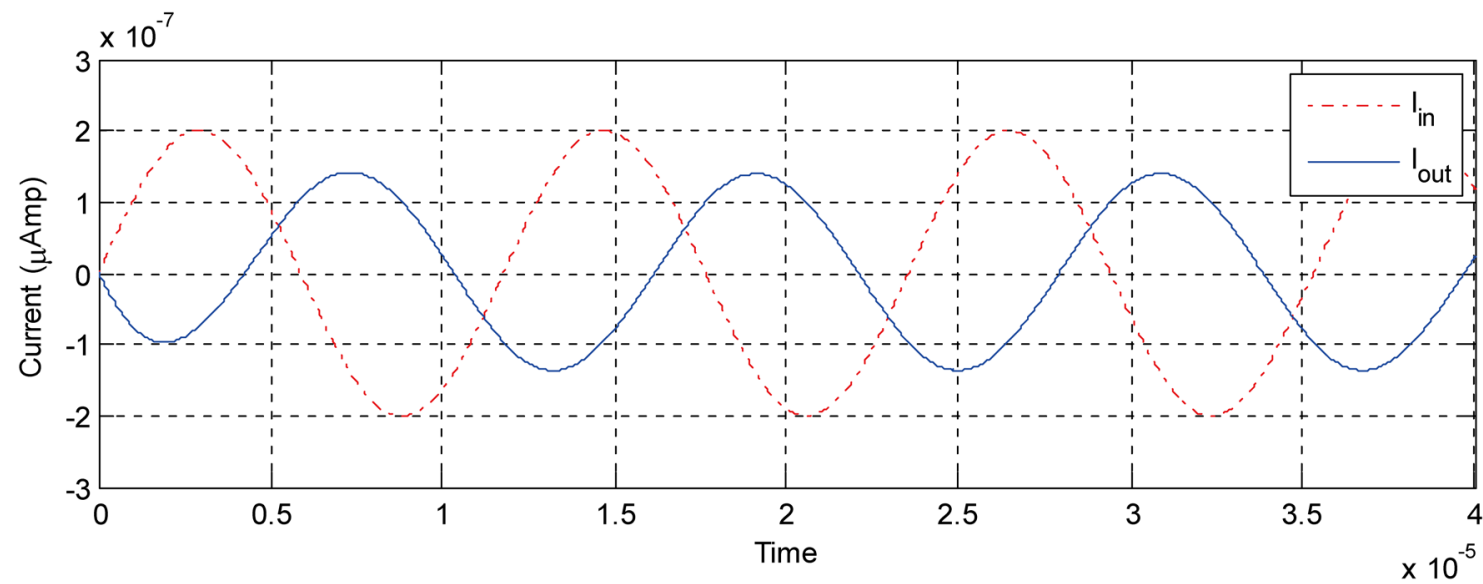

(b) 


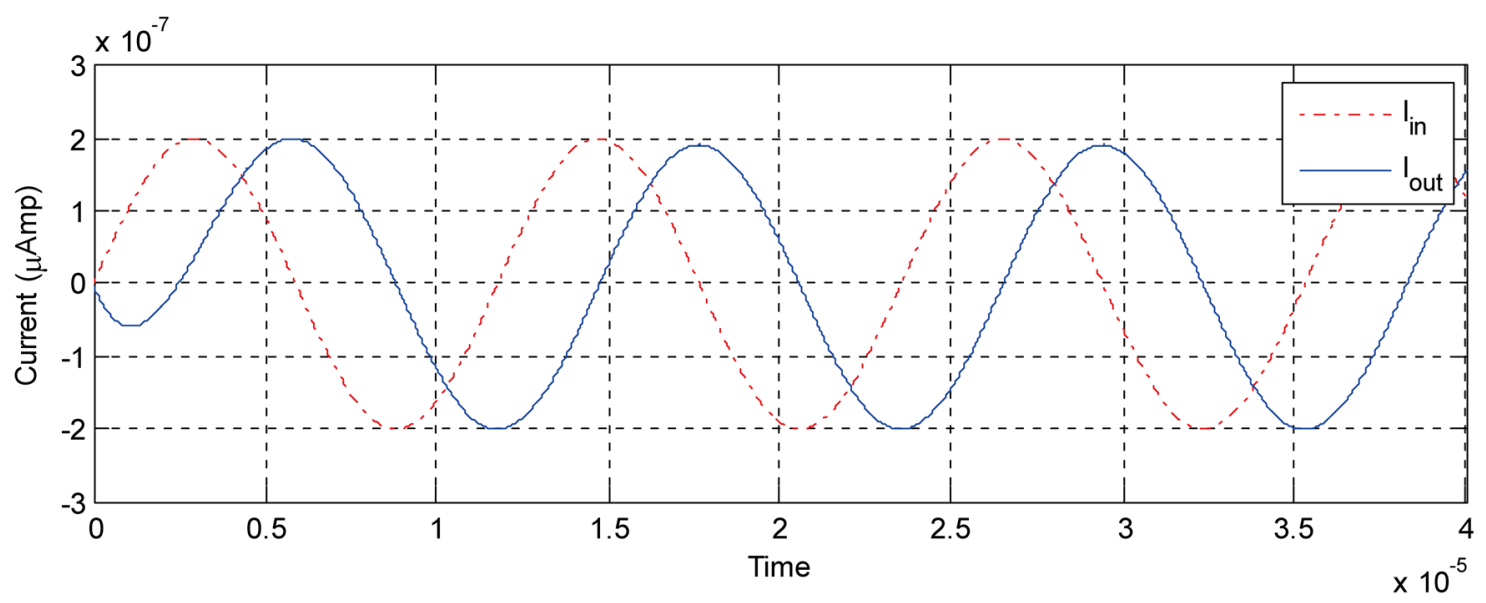

(c)

Figure 3. Transient response of various circuits: (a) Transisent response of low-pass filter $\left(f_{0}=85 \mathrm{KHz}\right)$; (b) Transient response of high-pass filter $\left(f_{0}=85 \mathrm{KHz}\right)$; (c) Transient response of all-pass filter $\left(f_{0}=85 \mathrm{KHz}\right)$.

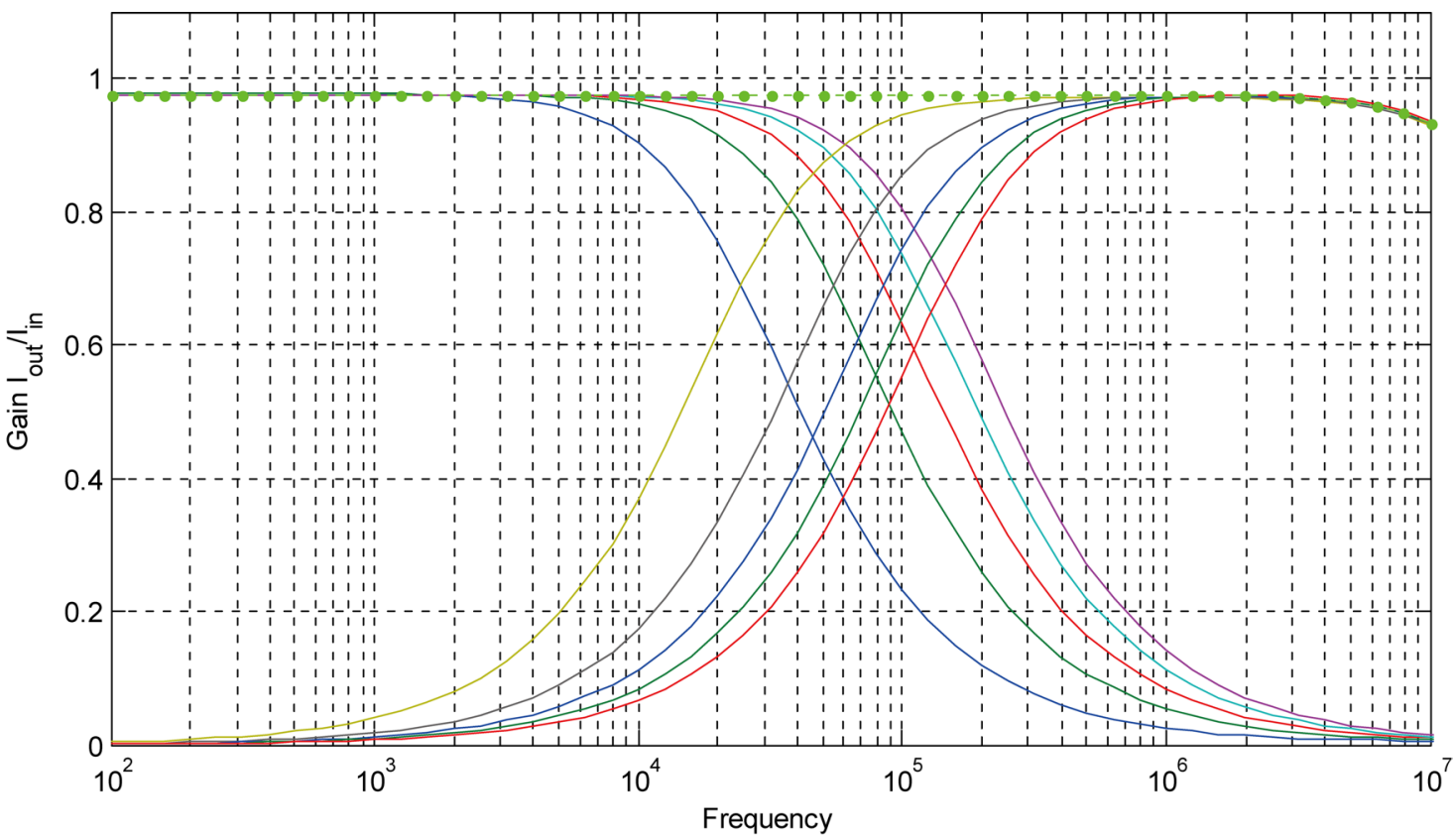

Figure 4. Electronically tuning characteristics observed by varying the current $I_{f}(20 \mathrm{nA}, 45 \mathrm{nA}, 70 \mathrm{nA}, 95 \mathrm{nA}$ and $200 \mathrm{nA})$.

low-pass, high-pass and all-pass. Figures 3(a)-(c) shows the transient response of the low-pass, high-pass and all-pass filters designed for cutoff frequency of $f_{0}=85 \mathrm{KHz}$ by taking $I_{f}=70 \mathrm{nA}$. Figure 4 shows the electronic controllability of the cutoff frequency by change of dc bias current $\left(I_{f}=20 \mathrm{nA}, 45 \mathrm{nA}, 70 \mathrm{nA}, 95 \mathrm{nA}\right.$ and $\left.120 \mathrm{nA}\right)$ and Figure 5 shows the phase response of the all-pass filter. The proposed circuit has been tested in $0.35 \mu \mathrm{m}$ technology has also been tested in $0.18 \mu \mathrm{m}$ technology as per the reviewer one. The results obtained where almost similar to results obtained by $0.35 \mu \mathrm{m}$ technology. In the all-pass response the cutoff frequency has been found better. 


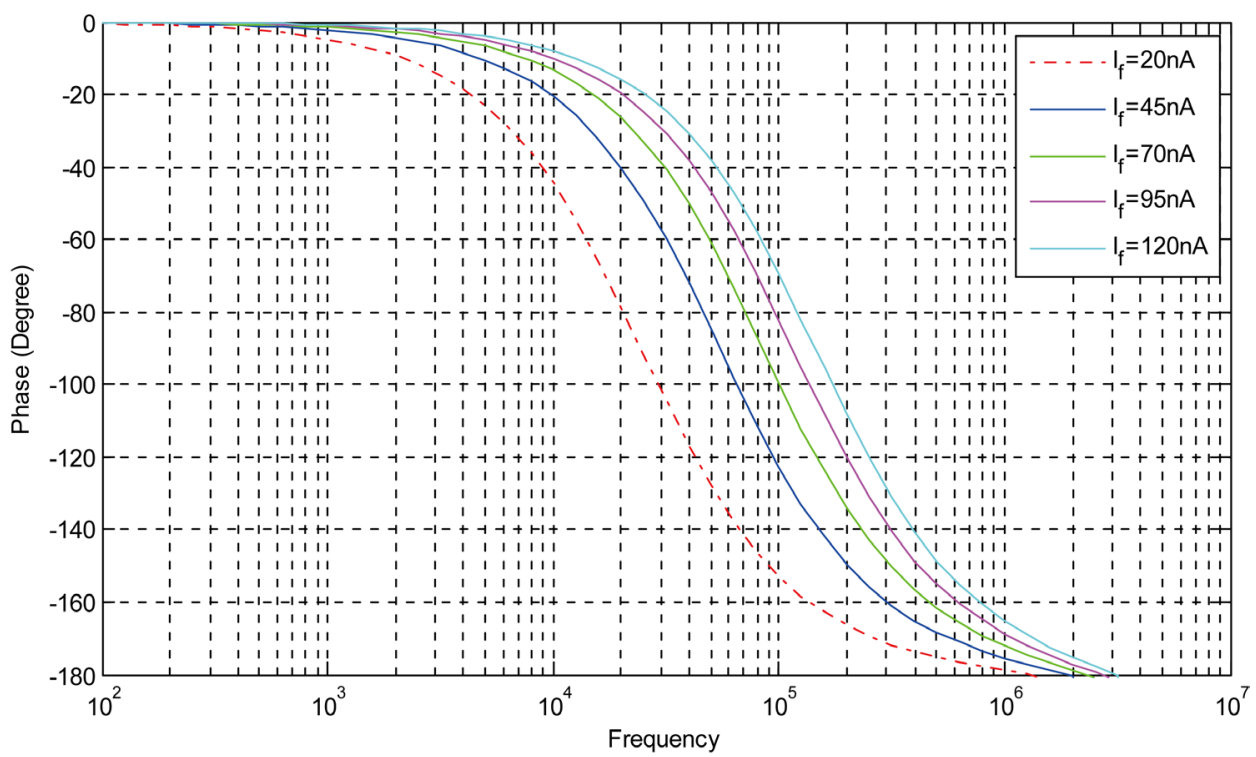

Figure 5. Phase response of the all-pass filter.

The SPICE simulation results, thus confirm the validity of the proposed filter.

\section{Concluding Remarks}

This paper presented a log-domain multifunction first-order filter using only MOSFETs and grounded capacitor. The circuit is capable of realizing all first-order filters namely, low-pass, high-pass and all-pass from the same configuration with electronic tunability of the radian frequency $\omega_{0}$. The circuit was simulated in SPICE employing TSMC 0.35 $\mu \mathrm{m}$ Level 3 CMOS process parameters. The SPICE simulation results have confirmed the workability and performance of the proposed MOS circuit. The proposed circuit which is operated from \pm 0.5 volt DC power supply and consumes only $2.62 \mu \mathrm{W}$ power at $I_{f}=120 \mathrm{nA}$, appears suitable for low voltage, low-power applications. This paper has therefore, added a new CMOS multifunction first-order filter to the existing repertoire of log-domain filters (as in [1]-[9] [16] and references cited therein).

\section{Acknowledgements}

Authors are thankful to "Analog Signal Processing Research Lab", Electronics Engineering Department, Institute of Engineering and Technology, Lucknow for conducting this research. The authors are also thankful to World Bank assisted project "Technical Education Quality Improvement Program" for funding this lab.

\section{References}

[1] Adams, R.W. (1979) Filtering in the Log-Domain. 63rd AES Conference, New York, May 1979, 4.

[2] Frey, D.R. (1993) Log-Domain Filtering: An Approach to Current-Mode Filtering. IEE Proceedings G-Circuits, Devices and Systems, 140, 406-416. http://dx.doi.org/10.1049/ip-g-2.1993.0066 
[3] Frey, D.R. (1996) Exponential State-Space Filters: A Generic Current-Mode Design Strategy. IEEE Transaction on CAS-I: Fundamental Theory and Applications, 43, 34-42. http://dx.doi.org/10.1109/81.481459

[4] Tsividis, Y.P., Gopinathan, V. and Toth, L. (1990) Companding in Signal Processing. Electronics Letters, 26, 1331-1332. http://dx.doi.org/10.1049/el:19900858

[5] Seevinck, E. (1990) Companding Current-Mode Integrator: A New Circuit Principle for Continuous-Time Monolithic Filters. Electronics Letters, 26, 2064-2065.

http://dx.doi.org/10.1049/el:19901319

[6] Toumazou, C., Ngarmnil, J. and Lande, T.S. (1994) Micropower Log-Domain Filter for Electronic Cochlea. Electronics Letters, 30, 1839-1841.

http://dx.doi.org/10.1049/el:19941284

[7] Jain, M.K., Singh, V.K. and Senani, R. (2015) A Bibliography of the Work Done on Externally-Linear-Internally-Nonlinear Circuits during 1979-2014. American Journal of Electrical and Electronic Engineering, 3, 64-71.

[8] Kircay, A. and Cam, U. (2006) Log-Domain First Order Multifunction Current-Mode Filter Design. IEEE 14th Signal Processing and Communications Applications, Antalya, 17-19 April 2006, 1-4.

[9] Kircay, A. and Cam, U. (2006) A Novel Log-Domain First Order Multifunction Filter. ETRI Journal, 28, 401-404. http://dx.doi.org/10.4218/etrij.06.0205.0117

[10] Arslanalp, R., Tola, A.T. and Yuce, E. (2011) Novel Resistorless First-order Current-Mode Universal Filter Employing a Grounded Capacitor. Radioengineering, 20, 656-664.

[11] Arslanalp, R., Tola, A.T. and Yuce, E. (2011) Fully Controllable First Order Current Mode Universal Filter Composed of BJT and a Grounded Capacitor. Electronics and Electrical Engineering, 6, 69-72. http://dx.doi.org/10.5755/j01.eee.112.6.448

[12] Kircay, A. (2014) Electronically Tunable-Current-Mode Square-Root-Domain First-Order Multifunction Filter. International Journal of Electronics, 101, 212-219. http://dx.doi.org/10.1080/00207217.2013.778172

[13] Horng, J.W., Hou, C.L., Tseng, C.Y., Chang, R. and Yang, D.Y. (2012) Cascadable Current-Mode First-Order and Second-Order Multifunction Filters Employing Grounded Capacitors. Active and Passive Electronic Components, 2012, Article ID: 261075. http://dx.doi.org/10.1155/2012/261075

[14] Pal, R., Tiwari, R.C., Pandey, R. and Pandey, N. (2014) Single CDBA Based Current Mode First Order Multifunction Filter. International Journal of Engineering Science and Technology (IJEST), 6, 444-451.

[15] Andreou, A.G., Boahen, K.A., Pouliquen, P.O., Pavasovic, A., Jenkins, R.E. and Strohbehn, K. (1991) Current-Mode Subthreshold MOS Circuits for Analog VLSI Neural Systems. IEEE Transactions on Neural Networks, 2, 205-213. http://dx.doi.org/10.1109/72.80331

[16] El-Marsy, E.I. and Wu, J. (1999) CMOS Micropower Universal Log-Domain Biquad. IEEE Trans. CAS-I: Fundamental Theory and Applications, 1, 389-392.

[17] Metin, B., Herencsar, N. and Vrba, K. (2012) A CMOS DCCII with a Grounded Capacitor Based Cascadable All-Pass Filter Application. Radioengineering, 21, 718-724. 
Submit or recommend next manuscript to SCIRP and we will provide best service for you:

Accepting pre-submission inquiries through Email, Facebook, LinkedIn, Twitter, etc. A wide selection of journals (inclusive of 9 subjects, more than 200 journals)

Providing 24-hour high-quality service

User-friendly online submission system

Fair and swift peer-review system

Efficient typesetting and proofreading procedure

Display of the result of downloads and visits, as well as the number of cited articles

Maximum dissemination of your research work

Submit your manuscript at: http://papersubmission.scirp.org/ 